\title{
Keinonainen Turingin (sukupuoli)testissä
}

\author{
Sara Heinämaa
}

Aion pohtia erästä vanhaa filosofista ongelmaa: filosofian suhdetta naiseen, tarkemmin sanottuna naisellisiksi käsitettyihin ilmiöihin. Lähtökohtani on aatehistoriallinen naistutkimus, erityisesti Evelyn Fox Kellerin, Genevieve Lloydin ja Luce Irigarayn työt. ${ }^{1}$ Otan lähtökohdaksi väitteen, jonka olen abstrahoinut näiden naisfilosofien teksteistä: naisellinen on suljettu pois filosofisesta diskurssista, erityisesti tietoa koskevasta filosofisesta diskurssista ja pyrin osoittamaan, ettei tämä poissulkeminen ole vain menneitten vuosisatojen ongelma.

Olen valinnut tarkasteluni kohteeksi erään tietyn filosofisen diskurssin, ajattelun ja tiedon luonnetta koskevan kognitiotieteellisen keskustelun. Tätä keskustelua käydään erittäin kuumeisesti sekä Yhdysvalloissa että Euroopassa, kyse ei siis ohitetusta filosofisesta vaiheesta. Pyrin näin ollen osoittamaan, että naisellisen poissulkeminen on käynnissä oleva diskursiivinen prosessi ja että poissulkemisella on sisällöllistä merkitystä.

\section{Jerry Fodorin "Luontoäiti"}

Yksi kognitiotieteen vaikutusvaltaismmista filosofeista on yhdysvaltalainen Jerry Fodor. Fodor on 1970-luvulta lähtien kehittellyt ja puolustanut tietokoneanalogiaan nojaavaa teoriaa ajattelun luonteesta. Fodorin mukaan ajattelu on olennaisesti komputaatiota, laskentaa, siis periaatteessa samankaltainen prosessi, minkä tietokoneet toteuttavat. ${ }^{2}$

Uudessa vuonna 1990 ilmestyneessä artikkelikokoelmassaan $A$ Theory of Content and Other Essays Fodor näkee komputaatioteorian ratkaisevana ongelmana kysymyksen, voidaanko teoriaan liittää vakuuttava naturalistinen selitys ajattelun intentionaalisuudesta. ${ }^{3}$ Fodor esittää oman myönteisen ratkaisunsa teoksensa ensimmäisessä osassa, mutta pyrkii sitä ennen viemään pohjan vaihtoehtoisilta ratkaisuilta, erityisesti eräiltä informaatioteoreet- tisilta merkityksen teorioilta. Hän kritisoi informaatioteoreettisia ratkaisuyrityksiä siitä, että ne joutuvat vetoamaan luonnon teleologiaan vastatessaan kysymykseen, miten päättelyrooleiltaan samanlaiset mielensisällöt voidaan erottaa toisistaan. Fodorin keskustelu luonnonteleologiasta etenee muun muassa seuraavasti:

"As we have seen, it's quite unclear that appeals to 'what Mother Nature has in mind' can rationalize distinctions between reliably equivalent content attributions. Indeed you might put Brentano's thesis like this: The difference between Mother Nature and Granny is precisely that Granny does, and Mother Nature doesn't, honor merely intentional distinctions." 4

Kysymys, jota tällaiset tekstinpätkät herättävät, ei ole pelkästään: onko Fodorin Brentanotulkinta oikea tai ovatko informaatioteorioiden teleologiset selitykset ongelmattomia, vaan myös - ja ehkä ennen muuta - miksi 1980luvun lopussa kirjoitettu teksti, jonka ei pitäisi koskea eri sukupuolia, vaan Fodorin omien sanojen mukaan ihmisluonnon muuttumatonta rakennetta, erityisesti sen intentionaalisuutta ${ }^{5}$, samastaa ei-intentionaalisen luonnon naiseen, ja tarkemmin ottaen äitiin. Onko tämä samastus sisällöllisesti merkittävä vain onko se pelkästään tyylillinen tehokeino.

Fodor asettaa epäinhimillistä ei-intentionaalista luontoa vastaan intentionaalisen naisihmisen, Granny-nimisen isoäidin. Pelkkä luonnon ja äidin välinen assosiaatio ei näin ollen tee intentionaalisuutta miespuoliseksi piirteeksi Fodorin tekstissä. Luonnon ja isoäidin suhde on kuitenkin vain osa Fodorin piirtämästä kuvasta. Kahden naisen lisäkseen Fodor esittelee täydellisen järkevän, kaikkitietävän miesjumalan:

"So God can tell the intentional content of your neural state by looking at its actual 
relations and at the relevant counterfactuals; in effect, He can apply the method of differences, just like any other agent." 6

Vaikka siis Fodorin henkilöhierarkiassa Kaikkitietävän Mielen ja Mielettömän Luonnon väliin jää sukupuolisesti kaksiaineksinen alue, ovat hierarkian ääripäät sukupuolitetut: yksi on miespuolinen ja toinen naispuolinen.

Luontoäiti ja Isä Jumala eivät ole ainoa Fodorin käyttämä sukupuolimetaforat. Teoksesta löytyy myös muita nais- tai miespuolisia elementtejä. Se sisältää muun muassa kehyskertomuksen, jossa esiintyy älykäs, älyllisesti utelias setä Wilifred ja ajattelematon täti vailla nimeä. ${ }^{7}$

Vähintään yhtä merkityksellistä on, että Fodorin esittelemä ajattelun malli ei ole sukupuolineutraali. Fodorin mukaan ajattelu muistuttaa argumentaatiota sikäli, että molemmat prosessit ovat totuudensäilyttäviä. Lisäksi ajattelu on menestyksekkäintä silloin, kun sen sisältämät uskomukset ovat tosia. Fodor ei esitä perusteluja tälle näkemykselleen mutta antaa ymmärtää, että sellaisia löytyy evoluutioteoriasta: "Thinking - specifically, thinking true thoughts - is arguably the best way to achieve adaptivity that evolution has thus far devised." 8

Perustelujen sijasta Fodor esittää mallin. Paradigmaattinen ajattelija on hänen mukaansa fiktiivinen salapoliisi Sherlock Holmes, jonka mielenliikkeet etenevät kohti lopullista ratkaisua totuudensäilyttävien askelten kautta. Vastakohdaksi asettuvat muiden muassa James Joycen sankarittaret. Heidän päänsä eivät ehkä ole tyhjiä, niissä tapahtua kaikenlaisia vuorovaikutusta, ja mentaalinen vuorovaikutus on kieltämättä mentaalista toimintaa. Mutta kaikki mentaalinen toiminta - huomauttaa Fodor - ei ole ajattelua. ${ }^{9}$

Ajattelun, intentionaalisuuden ja älykkyyden kategoriat eivät siis Fodorin tekstissä ole sukupuolineutraaleja, mutta epäselvää on, mikä on sukupuolisten elementtien asema tekstin kokonaisuudessa. Ovatko samastukset sisällöllisesti merkittäviä vain ovatko ne pelkästään tyylillisiä tehokeinoja, joilla Fodor lähestyy yleisöään. ${ }^{10} \mathrm{Ja}$ mikä jälkimmäisessä tapauksessa on Fodorin olettama yleisö.

Minulla ei ole vastausta näihin kysymyksiin, enkä halua sellaista edes ennakoida. Sen sijaan aion pohtia kognitiotieteen sukupuolineutraaliutta tarkastelemalla tiettyä yleistä ideaa, joka esiintyy lähes kaikissa kognitiotieteen perusesityksissä, niin kutsuttua Turingin testiä. Turingin testin tarkoituksena on selvittää kysymys tietokoneen älykkyydestä ja ajattelukyvystä. Sen on yhtäältä väitetty ratkaisevan kysymyksen ja toisaalta osoittavan sen mielettömäksi.

Testi on naisellisen poissulkemisen kannalta mielenkiintoinen siksi, että Turing muotoili sen alunperin käyttäen hyväkseen sukupuolen kategoriaa, mutta testin myöhemmistä muotoiluista ja tulkinnoista sukupuoli on hävinnnyt.

\section{Turingin testi}

Turingin testi muodostuu eräänlaisesta jäljittelypelistä. Alkuperäisessä muotoilussa siihen tarvitaan yksi nainen, yksi mies, yksi ihminen, jonka sukupuolta ei määritetä, sekä yksi tietokone. ${ }^{11}$

Testin lähtökohtana on tilanne, jossa mies ja nainen ovat suljettuina kahteen huoneeseen, ja kolmas henkilö on huoneiden ulkopuolella. ${ }^{12}$ Kolmannen henkilön tehtävänä on selvittää kysymyksillä, kummassa huoneessa on nainen - ja kummassa mies. Hän ei kykene tekemään päätelmiä henkilöiden ulkomuodosta eikä heidän äänestään, sillä hän on yhteydessä heihin ainoastaan kaukokirjoittimen välityksellä.

$\begin{array}{lll}\text { Nainen? }_{\text {Huone }_{1}} & \longrightarrow \\ & \text { Kyselijä } & \begin{array}{l}\text { Mies } \\ \text { Huone }_{2}\end{array}\end{array}$


Turing näyttää olettavan, että totuus sukupuolista selviää suhteellisen ongelmattomasti heti, kun huoneitten ovet avataan, heti kun kyselijä kykenee näkemään, kuulemaan ja tunnustelemaan molempia henkilöitä. ${ }^{13}$ Jos kyselijä on päätellyt, että vasemmanpuoleisessa huoneessa on mies, ja jos huoneesta löytyy pitkähiuksinen, ehostettu, parfyymilta tuoksuva henkilö pukeutuneena leninkiin ja korkeisiin korkoihin, on kyselijä hävinnyt. Tai hän on hävinnyt melko todennäköisesti: kyseessä saattaa nimittäin olla myös miespuolinen transvestiitti tai transseksuaali. Viime kädessä sukupuolen kriteerinä näyttää tässä keskustelussa toimivan (miehen) sukupuolielimien läsnäolo ja puuttuminen, ei esimerkiksi geneettiset ja hormonaaliset tekijät. ${ }^{14}$

Turing antaa naiselle tehtäväksi auttaa kyselijää selvittämään ongelma, ja nainen suoriutuu tästä luultavasti parhaiten kertomalla totuuden. ${ }^{15}$ Miehen tehtävänä on sen sijaan estää kyselijää ongelman selvittämisessä, hän voi valehdella ja hämätä jäljittelemällä naisen vastauksia.

Jos kyselijä esimerkiksi kysyy huoneissa olevilta, oletko nainen, kannattaa naisen todennäköisesti vastata kyllä. Kysymys ei kuitenkaan onnistu tekemään eroa naisen ja miehen välille, sillä myös mies voi väittää olevansa nainen. Kyselijä voi tietenkin yrittää muotoilla ovelampia kysymyksiä, esimerkiksi: mitä huulipunaa käytät, pidätkö lihaksikkaista miehistä tai ovatko kuukautisesi kivuliaat. Hän voittaa pelin, jos kykenee selvittämään, kummassa huoneessa nainen on. ${ }^{16}$

Tähän asti pelin tulkinnasta ei ole epäselvyyksiä, mutta tähän asti testi ei myöskään sano mitään tietokoneista, niiden älykkyydestä tai ajattelukyvystä. Tulkintaongelmat alkavat kun siirrytään pelin toiseen, tietokoneita koskevaan, vaiheeseen. Turing kuvasi sitä sanomalla, että uudessa vaiheessa mies on vaihdettu tietokoneeseen.
Yleisesti hyväksytty tulkinta on, että kun mies poistuu pelistä, häviää myös naisen sukupuoli. Nainen ikään kuin muuttuu ihmislajin edustajaksi, ja peli alkaa testata ihmisen ja koneen välistä eroa.

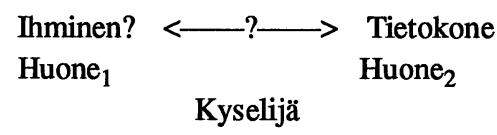

Esimerkiksi Eugene Charniak ja Drew McDermott kuvaavat muutoksen seuraavasti: "Similarly, Turing suggested we could have $a$ person in one room and a computer in other, both claiming to be a person." Vastaavasti James Fetzer siirtyy testin sukupuolettomaan versioon teoksessaan Philosophy and Cognitive Science: "Consider, for example, substituting an inanimate machine for the man. The question might then be changed to guessing which is the machine and which is the human being."17

Näin ymmärrettynä Turingin testi toimii melko suoraviivaisesti tietokoneen älykkyyden mittarina. Jos kyselijä ei onnistu erottamaan tietokonetta ihmisestä esittämällä näille kahdelle kysymyksiä, voimme sanoa, että kone on älykäs - samassa määrin kuin ihminen.

Tällaista sukupuoletonta versiota Turingin testistä esitellään yleensä tekoälyn ja kognitiotieteen johdantoteoksissa, ja sen avulla tutkitaan erilaisten tekoälyohjelmien henkistä tasoa. Esimerkiksi niinkin typerän ohjelman kuin psykoterapeuttia jäljittelevän ELIZAn on väitetty selviytyvän Turingin testistä, ja tulkitsijasta riippuen tämä on luettu joka ELIZAn nerokkuuden ansioksi tai osoitukseksi Turingin testin mielettömyydestä. Muun muassa ELIZAn rakentaja Joseph Weizenbaum on joutunut hämmästelemään ohjelmansa luomaa illuusiota. Hän kirjoittaa:

"ELIZA created the most remarkable illusion of understanding in the minds of the people who conversed with it...They would often 
demand to be permitted to converse with the system private, and would, after conversing with it for a time, insist, in spite of my explanations, that the machine really understood them." 18

$\begin{array}{lll}\text { Terapeutti? }_{\text {Huone }_{1}} & \longrightarrow ? \longrightarrow & \begin{array}{l}\text { ELIZA } \\ \text { Huone }_{2}\end{array}\end{array}$

Sukupuoleton Turingin testi siis näyttää päästävän lävitseen systeemejä, joita niiden suunnittelijat pitävät melko älyttöminä. ${ }^{19}$

Charniak ja McDermott esittävät kuitenkin varauksen testin sukupuolettomaan tulkintaan. He huomauttavat, että Turingin artikkeli on tässä suhteessa epäselvä. Teksti näyttää sanovan, että tietokoneen tehtävänä on jäljittellä naista, ei ihmistä yleensä. Epäselvyyden vuoksi he kuitenkin päätyvät kannattamaan sukupuoletonta tulkintaa, ja päättelevät — useimpien muiden tavoin - että Turingin tarkoituksena oli asettaa vastakkain tietokone ja ihminen, ei tietokonetta ja naista. ${ }^{20}$

Mutta entä jos tämä yleisesti hyväksytty tulkinta onkin virheellinen? Entä jos sukupuolet olivat Turingin testijärjestelyjen kannalta olennaisia? Tarkoituksenani ei ole ryhtyä väittelemään Turingin tekstin yksityiskohdista eikä Turingin alkuperäisistä tarkoituksista, vaan ainoastaan sitä, onko sukupuolen huomioon ottava tulkinta mahdollinen. Haluan kysyä, miten sukupuolen säilyttäminen vaikuttaa testin rakenteeseen ja siihen, millaiset systeemit läpäisevät sen. Tarkoituksenani on osoittaa, että sukupuolilla on merkitystä testille ja erityisesti testin sisältämälle väitteelle älyllisten ja fyysisten ominaisuuksien suhteesta.

\section{Tulkinta, joka ottaa huomioon sukupuolen...}

Näkemykseni mukaan sukupuolieron säilyttävä testiversio on ehdollinen vahvemmassa mielessä kuin versio, josta sukupuolet on hävi- tetty. Yksinkertaistaen sukupuoleton versio sanoo, että kone-ihminen-pelin voittanut tietokone on ihmisen veroinen älykkyydessä.

Sukupuolinen versio sen sijaan sanoo, että kone-nainen-pelin voittanut tietokone on (nais)ihmisen veroinen älykkyydessä sikäli kuin mies-nainen-pelin voittanut mies on naisen veroinen naisena olemisessa. Ajatuksena on, että älykkyys on samassa määrin tietokoneen saavutettavissa kuin missä naisellisuus on miehen saavutettavissa, ts. älykkyys on samassa määrin riippumatonta ihmisruumiista kuin naisellisuus on riippumatonta naisruumiista. Kyse on analogiasta, kahta suhdetta verrataan toisiinsa.

Sukupuolisen ja sukupuolettoman testin eroa voi valaista jäljittelyn käsitteen avulla. Sukupuolettomassa versiossa testataan, sekoittaako kyselijä jäljitelmän, ts. keinotekoisen persoonan, todelliseen henkilöön. Sukupuolisessa versiossa sen sijaan selvitetään, sekoittaako kyselijä koneen esittämän naisjäljitelmän todelliseen naiseen yhtä usein kuin hän sekoittaa miehen esittämän naisjäljitelmän todelliseen naiseen. ${ }^{21}$ Sukupuoleton version koostuu yhdestä pelistä, mutta sukupuolinen versio kahdesta: kyselijää auttava nainen joutuu ensin pelaamaan miestä vastaan ja sitten tietokonetta. Jos siis sukupuoleton versio testaa eroa, testaa sukupuolen säilyttävä versio erojen eroja.

$$
\begin{aligned}
& \text { Nainen? } \longrightarrow \text { Mies } \quad \text { Nainen? } \longrightarrow \text { Tietokone } \\
& \text { Huone }_{1} \text { Huone }_{2} \text { Huone }_{1} \text { Huone }_{2} \\
& <\text {-? } \\
& \text { Kyselijä Kyselijä }
\end{aligned}
$$

Jos esimerkiksi ELIZAa olisi testattu sukupuolisen mallin mukaan, tulos ei ehkä olisi ollut suosiollinen ELIZAlle. Kyselijä olisi ensin joutunut pelaamaan terapeuttia jäljittelevää todellista henkilöä vastaan ja vasta tämän jälkeen ELIZAa vastaan. Hän olisi näin ollen päässyt vertaamaan kahta jäljitelmää toisiinsa sekä to- 
delliseen terapeuttiin, sen sijaan että olisi verrannut tietokonejäljitelmää pelkästään todelliseen terapeuttiin. ${ }^{22}$

$\begin{array}{lc}\text { Terapeutti? } \longleftrightarrow \text { Ihminen Terapeutti? } \longleftrightarrow \text { ELIZA } \\ \text { Huone }_{1} \longrightarrow \text { Huone }_{2} \text { Huone }_{1} & \text { Huone }_{2} \\ & \longleftrightarrow-? \longrightarrow\end{array}$

Kyselijä Kyselijä

Turing huomautti, että hänen testinsä etuna on, että se vetää selvän rajan ihmisen fyysisten ja älyllisten kykyjen välille. ${ }^{23}$ Tämän on yleensä tulkittu puolustavan jyrkkää eroa ihmismielen ja ihmisruumiin välillä. Kognitiotieteen klassinen idea on, että ajatteluohjelmisto saattaa toteutua myös ihmisruumiista radikaalisti eroavassa materiaalisessa perustassa, esimerkiksi tietokoneessa, enkeleissä tai vielä tuntemattomista alkuaineista muodostuneissa marsilaisissa. ${ }^{24}$

Testin sukupuoleton luenta kannattaa tällaisia väitteitä. Mutta jos säilytämme sukupuolet testissä, on testi rakenteeltaan analoginen, ja voimme tulkita myös riippumattomuuden idean analogiaksi. Testi väittäisi tällöin, että ihmisen älylliset kyvyt ovat riippumattomia hänen fyysisestä olemuksestaan samassa määrin kuin sosiaalinen naiseus on riippumatonta biologis-anatomisesta naispuolisuudesta. 25 Kysymykseksi nousee nyt, missä määrin erilaiset sukupuoliominaisuudet ovat riippumattomia siitä fyysisestä, materiaalisesta ruumiista, joka toteuttaa ne.

Turingin testiä ei tietääkseni koskaan ole järjestetty. Miehiä, naisia ja tietokoneita ei ole asetettu vastakkain testin edellyttämällä tavalla. Syynä on muun muassa se, että olemassa olevat tekoälyjärjestelmät ovat kaukana koneista, jotka kykenevät, edes hetkeksi, hämäämään normaalijärkistä kyselijää. Testit, joihin systeemit on alistettu, ovat Turingin testin erilaisia typistettyjä versioita. Ihmisiltä on esimerkiksi kysytty, kenen kanssa he uskovat keskustelevansa, kun he ovat puhuneet tieto- koneelle. Konetta ei siis ole asetettu todellisia ihmisiä varten, vaan ihmisten kuvitelmia vasten.

Näin ollen meillä ei ole testattua tietoa sen enempää siitä, kuinka hyvin miehet menestyvät naisten jäljittelyssä, kuin siitä, miten hyvin tietokoneet menestyvät naisia jäljittelevien miesten jäljittelyssä. ${ }^{26}$ Keskustelu on siis käytävä periaatteellisella tasolla.

Feminismi on perinteisesti vastustanut biologista determinismiä ja puolustanut näkemystä, jonka mukaan biologinen sukupuoli ei määrää ihmisen henkisiä, mentaalisia ominaisuuksia. Simone de Beauvoir aloittaa Toinen sukupuoli -teoksensa toisen osan sanoilla: "Naiseksi ei synnytä, naiseksi tullaan."27

de Beauvoirin periaate on tulkittu konstruktivistiseksi näkemykseksi, jonka mukaan sosiaalinen sukupuoli on se merkitys tai tulkinta, jonka biologinen sukupuoli saa yhteiskunnassa ja kulttuurissa. ${ }^{28} \mathrm{Ja}$ samalla lailla kuin missä tahansa merkkisuhteessa myös tässä merkin ja merkityn suhde on satunnainen ja muuttuva.

Koska sosiaalinen konstruktivismi painottaa sosiaalisen sukupuolen riippumattomuutta suhteessa anatomiaan, on sen ennuste naista jäljittelevälle miehelle lupaava: peniksellä varustettu ihminen käy sosiaalisesti naisesta (lähes) yhtä hyvin kuin penistä vailla oleva ihminen. ${ }^{29}$ Seurauksena tällaisesta vapaamielisyydestä teoria joutuu edellyttämään tietokoneelta melkoisia kykyjä: osoittaakseen miesihmisen veroista älykkyyttä ja ajattelukykyä pitäisi myös koneen käydä naisesta lähes kaikissa sosiaalisissa tilanteissa.

Biologisesta determinismistä sen sijaan seuraa, että mies tuskin koskaan kykenee onnistuneesti väittämään olevansa nainen. ${ }^{30}$ Biologian ja käyttäytymisen välille oletettu kausaaliketju estää onnistuneet jäljitelmät. Näin ollen biologinen determinismi ei edellytä tietokoneelta kovinkaan ihmeellisiä kykyjä: koska mies on (oletuksen mukaan) huono naisen jäljittelijä, ei koneenkaan tarvitse onnistua mon- 
taa kertaa naisen esittämisessä tullakseen luokitelluksi ihmisen veroiseksi älykkyydessä.

Vaikka lähes kaikki feministiset teoriat hylkäävät jyrkän biologisen determinismin, ei sosiaalinen konstruktivismi ole feminismin perustava lähtökohta. Uudempi naisliike ja -tutkimus on asettanut kyseenalaiseksi teorian perustana olevan biologisen ja sosiaalisen sukupuolen välisen erottelun. ${ }^{31}$ Sen on muun muassa väitetty toistavan radikaalia biologian ja kulttuurin välistä vastakkainasettelua ${ }^{32}$, sekä klassista ruumis/mieli-jakoa ${ }^{33}$.

Uudemmat naiseutta ja lesboutta koskettavat teoriat sen sijaan näkevät myös biologisen sukupuolieron diskurssien tuotteena. Yhteisenä lähtökohtana näillä teorioilla on Michel Foucault'n seksuaalisuutta koskevat tekstit. ${ }^{34}$ Biologinen suku-puoli on niiden mukaan kulttuurikonstruktio, ja se on tuotettu, ja sitä tuotetaan edelleen, seksuaalisuuden säätelemiseksi ja hallitsemiseksi. ${ }^{35}$

Turingin riippumattomuusanalogian naiseutta koskeva osa ei siis ole lainkaan ongelmaton, vaan siitä käydään vakavaa keskustelua. Analogian tulkinta riippuu niistä sukupuolisuutta koskevista taustaoletuksista, jotka määräävät tulkitsijan käsitystä biologisen ja sosiaalisen sukupuolen välisestä erottelusta. ${ }^{36}$ Väitän, että moderni kognitiontutkimus ei ole aivan niin sukupuolineutraalia kuin mitä yleensä halutaan uskoa - ja uskotella.

\section{Viitteet}

1. Ks. esim. Lloyd 1984; Irigaray 1985; Keller 1985; Whitford 1989; 1991.

2. Fodor 1975 s. 27; 1990 s. 28.

3. Fodor 1990 s. 13, 24-28.

4. Fodor 1990 s. 78 , kursiivi minun.

5. Fodor 1990 s. 205-206.

6. Fodor 1990 s. 127.

7. Fodor 1990 s. 3-28. Fodorin tarinassa on myös isoäiti, joka kannattaa Fodorin ideoita, mutta dogmaattisesti, argumenteista piittaamatta. Isoäiti on Fodorin tapaan konservatiivi, mutta ei pyri perustamaan kantaansa rationaaliseen argumentaa- tioon (s. 231-251).

8. Fodor 1990 s. 227, vrt. s. 27, 129.

9. Fodor 1990 s. 21.

10. Vrt. Niiniluoto 1984 s. 40; Harding 1986 s. 24.

11. Poikkean seuraavassa Turingin esityksestä sikäli, että en merkitse miestä A:lla, naista B:llä ja kolmatta henkilöä, ns. kyselijää, C:llä. Hylkään tämän merkintätavan siksi, että se jättää sukupuolen ja sen vaikutukset näkymättömiin testissä.

Kolmannen pelaajan, kyselijän, sukupuolta ei siis määritetä. Turing viittaa häneen maskuliinipronominilla "he", mutta sanoo, että kyselijä "voi olla kumpaa sukupuolta tahansa". (Turing 1964 s. 5.) Näin ollen Turing, kyselijään viitatessaan, käyttää tai pyrkii käyttämään pronominia "he" sen sukupuolineutraalissa merkityksessä. (Ks. pronominin "he" sukupuolineutraalista käyttötavasta esim. Heinämaa ja Saarinen 1984 s. 72-87.)

12. Itse asiassa Turingin näyttää kuvaavan tilanteen, jossa kyselijä on suljettu yhteen huoneeseen ja mies ja nainen yhdessä toiseen: 'The interrogator stays in a room apart from the two." (Turing 1964 s. 5.) Tämä yksityiskohta ei kuitenkaan ole merkityksellinen seuraavan keskustelun kannalta.

13. Turing kuvaa testin ehtoja sanomalla, että ne "estävät kyselijää näkemästä ja koskemasta muita pelaajia, ja kuulemasta heidän ääniään." (Turing 1964 s. 6.)

14. Vrt. esim. Flax 1990a s. 24; 1990b s. 49-52. Erilaisista sukupuolten erottamiskriteereistä ks. esim. Devor 1898 s. 1-21; Kaplan and Rogers 1990.

15. Hoivatehtävä? (Ks. esim. Gilligan 1982.)

16. Turing 1964 s. 5, kursiivi minun.

17. Fetzer 1991 s. 23 , kursiivi minun.

18. Weizenbaum 1987 s. 189.

19. Testi johon ELIZA on alistettu ei kuitenkaan vastaa edes Turingin testin edellä kuvauttua sukupuoletonta versiota. Sen sijaan, että ihmisiä olisi pyydetty erottamaan ELIZA todellisesta terapeutista tai edes todellisesta henkilöstä, heiltä on kysytty yksinkertaisesti, kenen kanssa he uskovat puhuneensa, kun he ovat puhuneet ElIzan kanssa. Toisin sanoen ihmisiä on pyydetty vertaamaan ELIzAn vastauksia heidän omiin mielikuviinsa terapeutista, ei kehenkään terapeuttiin:

$$
\begin{aligned}
& \text { ELIZA } \\
& \text { Huone } \\
& \text { Kyselijä }
\end{aligned}
$$

Tuloksena on tietenkin ollut, että monet uskovat puhuneensa todellisen psykoterapeutin kanssa. 
20. Charniak ja McDermott 1985 s. 10.

21. Turing itse kuvasi siirtymää testin toiseen vaiheeseen seuraavasti: "We will now ask the question, 'What will happen when a machine takes the part of A (the man) in this game?' Will the interrogator decide wrongly as often when the game is played like this as he does when the game is played between a man and a woman? These questions replace our original, 'Can machines think?'" (Turing 1964 s. 5, sulut minun.)

22. Tai omiin kuvitelmiinsa terapeutista, kuten yleensä on tapana.

23. Turing 1964 s. 6.

24. Fodor 1975; Putnam 1980 s. 313, 413-424; Pylyshyn 1986; Churchland 1988; Fodor 1990.

25. Tarkkaan ottaen Turingin kysymys koskee pelkästään sosiaalisen sukupuolten verbaalisia, kirjallisia ilmenemiä: "In order that tones of voices may not help the interrogator the answer should be written, or better still, typewritten. The ideal arrangement is to have a teleprinter communicating between the two rooms." Keskustelun ulkopuolelle jäävät siis vaatetus, liikkeet ym., ts. kaikki muu paitsi verbaalinen käyttäytyminen. (Turing 1964 s. 5.)

26. Miespuolisten homoseksuaalien, transvestiittien ja transseksuaalien tulkitseminen naisten jäljittelijöiksi edellyttää vahvoja sukupuoliteoreettisia sitoumuksia ja on siten ongelmallista. (Ks. esim. Butler 1990 s. 31-34.)

27. Beauvoir 1980 s. 154.

28. Ks. esim. Butler 1990 s. 8; Kirby 1991 s. 5.

29. Sosiaalisesta konstruktionismista on erivahvuisia muotoja. Vahvimmillaan konstruktionismi on lähes yhtä determinististä kuin biologismi. Vaikka yksilön sosiaalinen sukupuoli ei vahvan sosiaalisen konstruktionismin mukaan ole kausaalisesti riippuvainen anatomisesta sukupuolesta, on se sosiaalis-kulturaalinen, tulkinnallinen, yhteys, joka postuloidaan anatomian ja sosiaalipsykologian välille, yhtä ehdoton kuin kausaalinen yhteys. Kuitenkin tällainen vahva sosiaalinen konstruktionismi on kulttuurirelatiivista siinä mielessä, että anatomisen sukupuolen sosiaalinen tulkinta vaihtelee sen mukaan suhteessa kulttuuriin ja/tai yhteiskuntaan. Näin ollen yksilö saattaa yhdessä kulttuurissa omaksua sosiaalis-psykologisia piirteită, jotka toinen kulttuuri liittää vastakkaiseen anatomiseen sukupuoleen.

30. Ks. esim. McMillan 1982 s. 88, 99; Griffiths 1989 s. 147. Myös Shulamith Firestone kannattaa jonkinasteista biologista determinismiä kirjoittaes- saan: "Nature produced the fundamental inequality - half of the human race must bear and rear the children of all of them - which was later consolidated, institutionalized, in the interests of men. Reproduction of the species cost women dearly, not only emotionally, psychologically, culturally but even in strictly material (physical) terms -."(Firestone 1988 s. 192, vrt. myös s. 221.)

31. Englanninkieleisessä keskustelussa puhutaan sex/gender -erottelusta. Biologiselle ja sosiaaliselle sukupuolelle on siis englannin kielessä omat terminsä: "sex" ja "gender". Mm. italialainen Rosi Braidotti on väittänyt, että erottelu ei näyttäydy yhtä luontevana eikä mielekkäänä niissä kieleissä, joista ei löydy erillisiä termejä biologiselle ja sosiaaliselle sukupuolelle. Hän antaa esimerkiksi romaaniset kielet, ranskan, espanjan ja italian, mutta myös suomen kieli kuuluu tähän luokkaan. (Braidotti 1991.)

32. Butler 1990 s. 6-7; McNay 1991 s. 129.

33. Flax 1990 b s. 50.

34. Vaikka naisteoreetikot ovat omaksuneet Foucault' 'lta perustavia lähtökohtia, sisältävät heidän kehitelmänsä myös vakavaa Foucault'hon kohdistuvaa kritiikkiä. (Ks. esim. de Lauretis $1987 \mathrm{~s}$. 14; Walby 1990 s. 117; McNay 1991 s. 131-133.)

35. Foucault 1978 s. 115; vrt. Butler 1990 s. 6-7, 23; Flax 1990a s. 25; Gatens 1991 s. 156; McNay 1991 s. 130-131.

36. Biologista ja sosiaalista sukupuolta koskevien epäselvyyksien lisäksi testin mahdollisia tulkintoja vaikeuttavat ne stereotyyppiset sukupuolikäsitykset, jotka ohjaavat niin pelin jäljittelijöiden, kyselijöiden kuin tuomareitten siirtoja. (Ks. sukupuolistereotyypeistä esim. Ashmore, Del Boca and Wohlers 1986.)

\section{Kirjallisuus}

Ashmore, Ricard D., Frances K. Del Boca and Arthur J. Wohlers 1986: "Gender Stereotypes". Richard D. Ashmore and Frances K. Del Boca (eds.): The Social Psychology of Female-Male Relations. A Critical Analysis of Central Concepts (s. 69-119). Academic Press. New York.

de Beauvoir, Simone 1980 (1949): Toinen sukupuoli. Lyhentäen suomentanut Annikki Suni. Kirjayhtymä. Helsinki.

Braidotti, Rosi 1991: "Gender and Post-Gender: The Future of an Illusion". Julkaisematon käsikirjoitus. Charniak, Eugene and Drew McDermott 1985: Introduction to Artificial Intelligence. Addison-Wesley 
Publishing Company. Reading, Massachusetts.

Churchland, Paul 1988 (1984): Matter and Consciousness. A Contemporary Introduction to the Philosophy of Mind. A Bradford Book. The MIT Press. Cambridge, Massachusetts.

Devor, Holly 1989: Gender Blending. Confronting the Limits of Duality. Indiana University Press. Bloomington and Indianapolis.

Fetzer, James 1991: Philosophy and Cognitive Scien$c e$. Paragon House. New York.

Firestone, Shulamith 1988 (1971): The Dialectic of Sex. The Case for Feminist Revolution. The Women's Press. London.

Flax, Jane 1990a: Thinking Fragments: Psychoanalysis, Feminism, \& Postmodernism in the Contemporary West. University of California Press. Berkeley, Los Angeles.

Flax, Jane 1990b: "Postmodernism and Gender Relations in Feminist Theory". - Linda J. Nicholson (ed.): Feminism/Postmodernism (s. 39-62). Routledge. New York and London.

Fodor, Jerry 1975: The Language of Thought. Massachusetts Institute of Technology. Thomas Y. Crowell Company. New York.

Fodor, Jerry 1990: A Theory of Content and Other Essays. A Bradford Book. The MIT Press. Cambridge, Massachusetts.

Foucault, Michel 1980 (1976): The History of Sexuality. Volume 1: An Introduction. Translated by Robert Hurley. Vintage Books. New York.

Gilligan, Carol 1982: In a Different Voice. Psychological Theory and Women's Development. Harvard University Press. Cambridge, Massachusetts.

Griffiths, Morwenna 1988: "Feminism, Feelings and Philosophy". - Morwenna Griffiths and Margareth Whitford (eds.): Feminist Percpectives in Philosphy (s. 131-51). Macmillan. Houndmills, Basingstoke.

Harding, Sandra 1986: The Science Question in Feminism. Cornell University Press. Ithaca and London.

Heinämaa, Sara ja Esa Saarinen 1984 (1983): Olennainen nainen. Naiskuvan filosofiset perusteet. Toinen painos. WSOY. Helsinki.

Irigaray, Luce 1985 (1974): Speculum of the Other Woman. Translated by Gillian C. Gill. Cornell University Press. Ithaca, New York.

Irigaray, Luce 1989: "Is the Subject of Science Sexed?". Translated by Carol Mastrangelo Bové. Nancy Tuana (ed.): Feminism and Science (p. 58-68). Indiana University Press. Bloomington. Suom. Pia Sivenius (1989): "Onko tieteen sub- jekti sukupuolitettu" (s. 147-62). - Sara Heinämaa (toim.): Naisen tieto. Art House. Helsinki.

Kaplan, Gisela T. and Lesley J. Rogers 1990: "The definition of male and female. Biological reductionism and the sanctions of normality". - Sneja Gunew (ed.): Feminist Knowledge. Critique and Construct (s. 205-228). Routledge. London and New York.

Keller, Evelyn Fox 1985: Reflections on Gender and Science. Yale University Press. New haven and London. Suom. Pia Sivenius (1988): Tieteen sisarpuoli. Vastapaino. Tampere.

Kirby, Vicky 1991: "Corporeal Habits: Addressing Essentialism Differently". - Hypatia vol.6, no.3 (Fall 1991) s. 5-24.

de Lauretis, Teresa 1987: Technologies of Gender. Essays on Theory, Film, and Fiction. Indiana University Press. Bloomington and Indianapolis.

Lloyd, Genevieve 1984: The Men of Reason. 'Male' and 'Female' in Westem Philosophy. Methuen. London.

McMillan, Carol 1982: Women, Reason and Nature. Some Philosophical Problems with Feminism. Basil Blackwell. Oxford.

McNay, Lois 1991: "The Foucauldian Body and the Exclusion of Experience". - Hypatia vol. 6, no. 3 (Fall 1991) s. 125-139

Niiniluoto, Ilkka 1984: "Totuuden rakastaminen". Esa Saarinen, Lilli Alanen ja Ilkka Niiniluonto (1984): Rakkauden filosofia (s. ). WSOY. Helsinki, Juva.

Putnam, Hilary 1980 (1960-1975): Mind, Language and Reality. Philosophical Papers. Volume 2. Cambridge University Press. Cambridge, London.

Pylyshyn, Zenon 1986: Computation and Cognition. Toward a Foundation for Cognitive Science. A Bradford Book. The MITPress. Cambridge, Massachusetts.

Turing, Alan 1964 (1950): "Computing Machinery and Intelligence". - Alan Ross Anderson (ed.): Minds and Machines (s. 4-30). Prentice-Hall, New Jersey.

Walby, Sylvia 1990: Theorizing Patriarchy. Basil Blackwell. Oxford, Cambridge.

Weizenbaum, Joseph 1987 (1976): Computer Power and Human Reason. Penguin Books. London.

Whitford, Margareth 1989: "Luce Irigaray's Critique of Rationality". Morwenna Griffiths and Margareth Whitford (eds.): Feminist Perspectives in Philosophy (s. 109-130). Macmillan. Houndmills, Basingstoke.

Whitford, Margareth 1991: Luce Irigaray - Philosophy and the Feminine. Routledge. London and New York. 